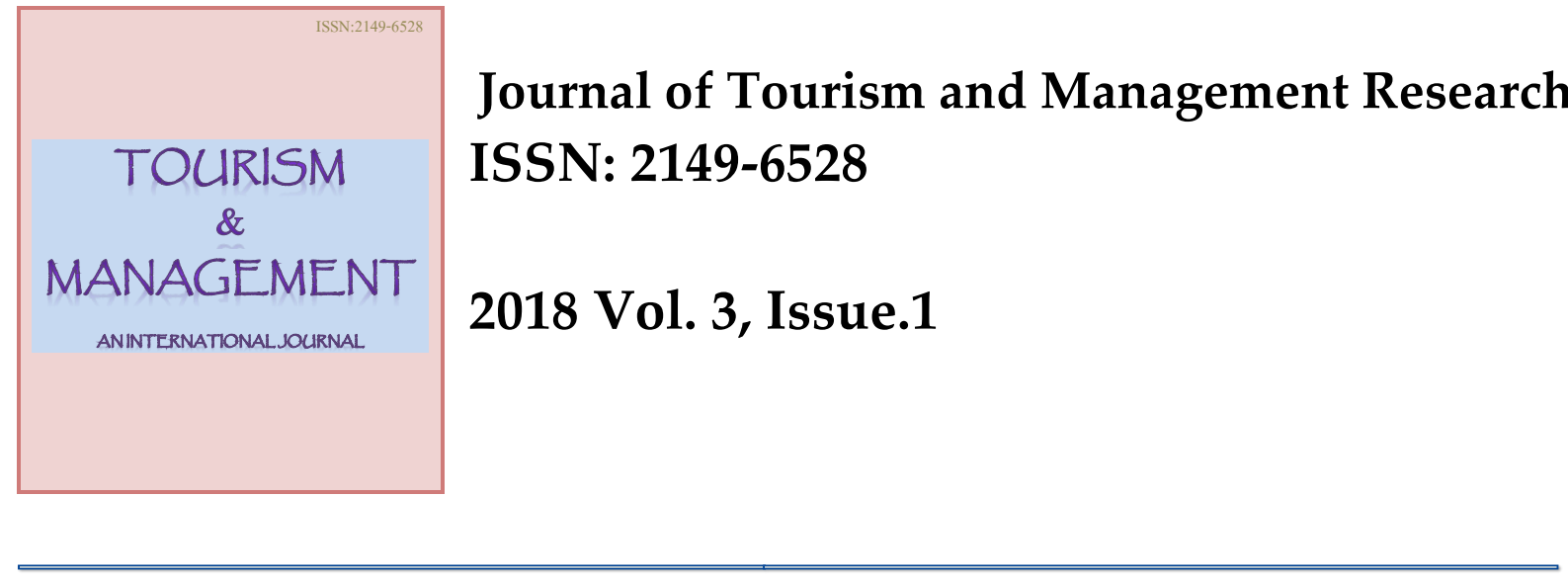

\title{
Healthy Eating Products and Customer Outcomes in Restaurants
}

\begin{abstract}
The purpose of this paper was to investigate the relationship between healthy eating products and customer outcomes such as increase in customer numbers, request for more products, satisfaction, and loyalty in restaurants. A cross-sectional analytical design was used to distribute 296 questionnaires to heads of departments drawn from 74 randomly sampled healthy eating restaurants in Nairobi, Kenya. The study established a significant relationship between healthy eating products and four different dimensions of customer outcomes. The research also reveals that meeting friends and convenience of restaurant location made a significant effect on customer outcomes. Healthy eating products to be offered in restaurants should include traditional, medicinal, products cooked using healthy cooking methods, vegetarian, gluten free and sea food products. The current study contributes to the theory of consumer behavior in the restaurant sector by clearly identifying products that customers consider as healthy foods. The study further reveals factors that attract customers to restaurants offering healthy eating products such as meeting friends and convenience of restaurant location. In this perspective, increase in information sharing made possible by technological advancements make it easier for people to form social groups and share ideas concerning eating out options.
\end{abstract}

Keywords: Healthy eating products, Customer outcomes, Restaurant, Consumer behavior, Food.

JEL Classifications: I12; I31; L83

Fwaya Erick Victor Onyango, PhD. (Corresponding Author). School of Hospitality \& Tourism Studies, The Technical University of Kenya, Box 52428 Nairobi 00200.

Email:erickfwaya@gmail.com

Tel: +254 (020) 343672, Fax: 2279689

Khasoa Carolyne Wasike, School of Hospitality \& Tourism Studies, The Technical University of Kenya, Box 52428 Nairobi 00200.

Email:caroshiu@gmail.com

Tel: +254 (020) 343672, Fax: 2279689 


\section{Introduction}

The rise in eating out trends symbolize changes which have occurred over the past several years ranging from an occasional treat to a regular occurrence whereby people do not just eat out to enjoy but seek healthy benefits from what they consume (Benalam, 2009). According to Legrand and Sloan (2006) these transformations have been influenced by lifestyle changes in addition to increased access to knowledge about health and nutrition. The shifts in customer expectations and needs have in turn made it more difficult for eating outlets and their employees to satisfy customer needs. When restaurant guests are presented with a choice between items labeled with and without healthy option, a reasonable number of customers choose the healthy choice menu items (Angell and Silver, 2008; Galliciano et al., 2012).

World Health Organization (2009) set the shift from earlier perceptions of eating when it estimated that by the year 2015, 700 million adults in the United Kingdom (UK) would be obese. Africa, probably because of rise in lifestyle diseases, has not been left behind in the consumer need for healthy eating products. The literature reveals estimated deaths of around 2.5 million from lifestyle related diseases in 2005 with a further projection of 28 million deaths over the proceeding 10 years in Africa (WHO, 2012). These deaths are mostly caused by life style diseases including cardiovascular (10\%), cancer (4\%), chronic respiratory (3\%), diabetes (4\%), maternal and per natal, nutritional disease $(70 \%)$ and other chronic diseases $(5 \%)$ (WHO, 2012).

Since nearly two-thirds of all deaths worldwide are caused by lifestyle related diseases (WHO, 2012), there exists a need to establish not just an alternative to medical disease prevention but also an expanded complementary consumer disease prevention sensitization. Galliciano et al. (2012) recommend that restaurants should take the lead in promoting healthy lifestyles. However, studies disclose that most restaurants are unfamiliar with the healthy eating concept and lack capacity to offer healthy eating products (Hwang and Lorenzen, 2008). Moreover, disparities in the consumer perspectives of what constitutes healthy eating are another source of misunderstanding that needs to be investigated. This is because earlier researchers erroneously defined healthy eating to be about fat and energy content of food. Most studies have focused on provision of nutritional information on menus overlooking the fact that labeling dishes with food values did not qualify them as healthy in the customers' perspective. Studies on healthy eating products as a tool for growing healthy eating market are also inadequate and do not necessarily reflect recent dynamics in healthy eating product consumers. The current study therefore, set out to achieve the following objectives: to identify the healthy eating products on offer in restaurants in Nairobi City County, Kenya; to examine the relationship between healthy eating products and customer outcomes such as increase in customer numbers, request for more products, satisfaction, and loyalty in restaurants in Nairobi, Kenya.

\section{Literature Review}

\subsection{Healthy Eating Concept Products on Offer in Restaurants}

Healthy eating products are produced by restaurants based on customers' ideas or perspectives of eating food that enables them to stay in good health or food that is perceived to prevent illnesses. Apparently, customers seeking long term services from restaurants consider provision of healthy eating products as a motivation for dinning out. In the past, lowfat foods and non-genetically modified ingredients were thought to be the main concern for consumers dining out (Josiam and Foster, 2009). However, literature indicates that healthy eating has become a broader concept that not only involves lifestyle trends but also other product categories that are presumed by consumers as healthy. Davies and Smith (2004) argue that among the factors which determine the healthy eating concept products on offer in eating outlets are "lifestyles which demand fast foods" (p.81). Consequently, products which were referred to as fast foods were those products on which customers spent less time consuming. 
Although these foods may be a "risk factor for gastrointestinal disturbances through eating quickly (Davies and Smith, 2004, p.82.), eating outlets prepare and group them under the healthy eating concept products (Legrand and Sloan, 2006). Legrand and Sloan (2006) were also concerned that most customers who sought low-fat foods and non-genetically modified ingredient foods were misled by outlets whose main objective was to sell what they would have prepared. As such restaurants took advantage of the vulnerability of the consumers to give false assurances on the attributes of their products, especially those grouped under the healthy eating concept product category.

More research findings on healthy eating concept products that consumers sought when dining out in restaurants globally indicate consumer focus on organic food products. For instance, in the USA eating out trends indicate a shift towards preference for healthier food products and particularly organic food products (Josiam and Foster, 2009). Zick et al. (2010) posit that apart from fat and energy components of food that consumers sought when dining out, there were other healthy benefits sought. The benefits sought after by consumers, according to these scholars entail information on saturated fat levels, polyunsaturated fat components, fiber and sodium levels in food. Research finding by earlier scholars on healthy eating products on offer in hotels show that consumers seek for, apart from calorie content of food, the salt level and saturated fat contents in the foods they sample while eating out (Mackison et al., 2009). Customers, therefore, expected that products on offer in restaurants were in terms of what they perceived to be healthy food. According to customers, these products included disease preventive products, products that helped manage illnesses, low fat/salt/sugar/calorie products, organic products, indigenous products, high fiber products, healthy cooked products as well as products that were healthy but required less time to eat among other customer perspectives.

Most eating outlets in the global set up are unfamiliar with healthy eating products (Hwang and Lorenzen, 2008). It is, therefore, not clear which products restaurants offer under the healthy eating concept product category or even the basis of the healthy eating products prepared in restaurants if there was any. This state of affairs confirms the necessity of an empirical study to determine what exactly constitutes healthy eating products.

\subsection{Healthy Eating Products and Customer Outcomes}

Research shows that customers sought to satisfy various needs as they sampled healthy eating products on offer in restaurants (Healthywise, 2017). Research findings indicate that although people have increased their frequency of eating out and their requests for healthy eating products when eating out most restaurants do not include healthy eating products as part of the products on offer. This is so even when the growth of healthy eating product market is pegged on the capacity of these facilities to offer healthy eating products that meet the needs of the healthy eating product market. The unique nature of this cadre of products is that, it is only the user who would gauge, rate and even rank outlets that offer healthy eating products. Customers respond to the healthy eating products on offer in restaurants because of satisfaction and loyalty. Research evidence shows that organizations that are customer focused are more likely to satisfy their customers and also benefit from repeat patronage of customers (Kotler, 2011). Repeat patronage by healthy eating product customers is only possible in cases where customer expectations have been met or surpassed. It may not, however be regular for restaurants to receive repeat patronage of healthy eating customers given that most restaurants are unfamiliar with healthy eating (Galliciano, et al., 2012). Customer response to healthy eating products is influenced by product attributes in relation to customer needs. Most eating outlets are, however, reported to have scarce knowledge, skills and capacity to offer healthy eating products that meet the needs of the healthy eating market (Galliciano et al., 2012; Mackison et la., 2009). It is unlikely that the healthy eating products on offer in restaurants could enhance customer outcomes among restaurants. Most studies 
concur that there are factors that influence customer needs for healthy eating products. However, there is no agreement concerning the set of factors that influence customer needs for healthy eating products. This study set out to investigate factors that influenced customer needs for this cadre of products in restaurants in Nairobi City County.

\subsection{Theoretical Issues Underpinning the Study}

The theory that informs this study is the Integrated Behavioral Model (IBM). This theory updates Reasoned Action theory (RA) and Planned Behavioral (PB) theory. The IBM proposes that intentions are the basic determinant of behavior. Apart from attitudes, subjective norms, and perceived self-efficacy which constitute intentions according to RA and PB theories, there are four additional components according to IBM which directly affect behavior: knowledge, salience of the behavior, environmental constraints, and habit. Subjective norms are behavioral attributes exhibited by an individual because of background factors like information and social factors (Fishbein and Ajzen, 2010). This study considers information and social factors that shape a person's behavior, attitudes and intentions in terms of education level, ease of access to nutritional information and customers' eating out experience to determine potential of healthy eating product. In this perspective, education level determines social groups to which an individual belongs as well as an individual's values and attitudes towards food choices. This study assumes that, the higher the education level, the stronger the influence from social groups and information sources (Fishbein and Ajzen 2010; Legrand and Sloan, 2006).

Attitude developed by this cadre of customers is that care has to be taken when eating out because the food choices a person makes has an impact on human health. The perceived norm will therefore be consumption of healthy food products based on the healthy benefits sought whereby the extent to which this behavior is exhibited depends on an individual's motivation (Lone et al., 2009; Tromp et al., 2007). Persons with higher educational levels are presumed to have increased access to information regarding illnesses that emanate from poor eating habits and how such illnesses can be prevented using appropriate food choices (Michaelidou and Hanssan, 2008). Eating outlets can, as such, predict customer intentions using the healthy benefits sought by customers. This includes, products that control blood sugar, control weight, blood sugar, prevent allergies, blood cleansing products among other benefits (Wu and Sturm, 2014). Alternatively, restaurants would predict customer intentions based on the customer needs or motives in terms of preventing illnesses that emanate from consumption of unhealthy food products. Restaurants that have potential to offer healthy eating products are better placed in prediction of customer intentions and behavior than those without (Scarpa, 2010).

Environmental factors influence consumer intentions affecting behavior. Based on the eclectic theories (IBM, RA and PB), behavioral intentions are predicted using social and information factors which also apply to healthy eating (Fishbein and Ajzen, 2010). However, the eclectic theories fail to account for location of the restaurant, age of restaurant and customer, type of restaurant, needs of the restaurant and the customer as well as restaurant ownership as significant factors in predicting behavior intentions (Cahill, 2006). With regard to type of restaurant, customers seeking healthy eating products in a fast food restaurant will find it difficult to control their behavior compared to those seeking the same products in specialty restaurants or even in general food product restaurants (Mamalis, 2009). Location is another factor that affects prediction of customer intentions in terms of food choices. Predicting intentions of customers who patronize restaurants located in areas with customers of higher education level, higher socio-economic status or within sporting areas will be easier given the population characteristics (Kim et al., 2006). In addition to restaurant type and location, ownership is a key factor in predicting the intentions of customers who patronize a restaurant. Owners who have a conviction of investing in healthy eating products are more likely to attract healthy eating customers therefore increasing their ability to predict intentions of 
customers, especially the healthy eating product customers (Pantelidis, 2010). Another factor that affects customer behavior, attitudes and customer intentions is age of a restaurant. Long established restaurants that have experience in customer needs, on the one hand, tend to have well trained staff who are better placed to plan and develop products that meet customer needs (Baker, 2006). Newly established restaurants, on the other hand, may be perceived by customers as trendy, therefore in touch with market eating trends hence better equipped to not only predict customer behavior but also influence their eating practices (Shaw, 2002).

\subsection{Conceptual Framework}

This section presents the conceptual framework of the study. Figure 1 is the conceptual framework of the study. Healthy eating products (products on offer and restaurant capacity) are the independent variables while customer outcomes (number of customers, request for more products, marketing, market awareness, satisfaction and loyalty) are the dependent variables. Age and size of the restaurant, location and population characteristics as well as restaurant ownership are the control variables.

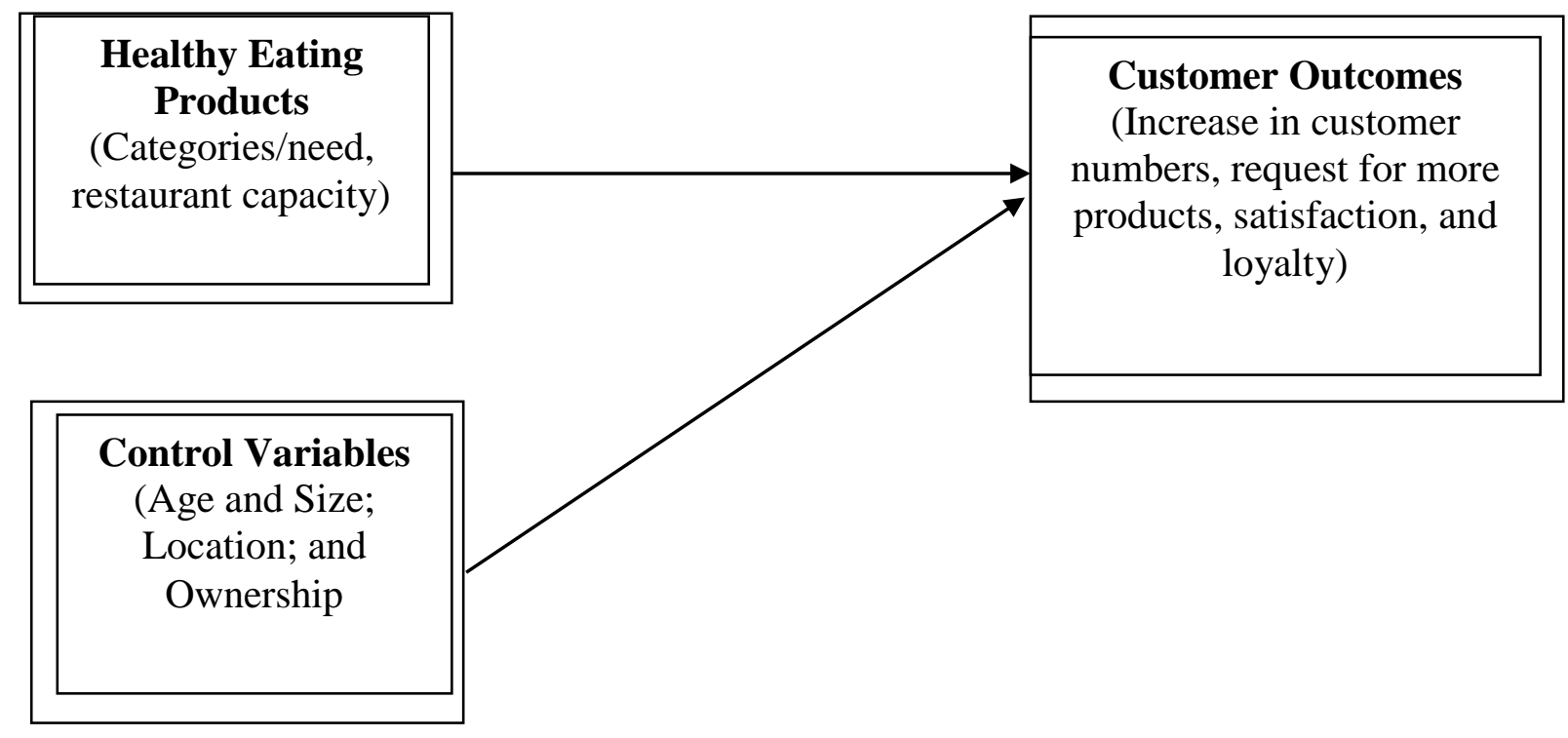

Figure 1: Conceptual framework.

The framework shows that customer outcomes are dependent on healthy eating products on offer. It is assumed that as long as restaurants have products that meet the needs of the market then the market is bound to grow. Customer response to positive attributes of healthy eating products is consistent with IBM. According this theory, customer behavior, attitudes and intentions are the product of social and information factors. Social groups that transfer information on healthy eating products on offer eventually influence growth of the healthy eating product market. According to this study, social groups seek healthy eating products because of nutritional information received on food choices and their impact on human health. Control variables were age of the restaurant, location and ownership. Age of restaurants was one of the intervening variables in the study. Long established restaurants may be perceived as experienced in terms of product development; market needs and have better capacity. These factors would be reflected in the healthy eating products on offer as well as customer outcomes. Newly established restaurants on the other hand were perceived by customers as trendy, therefore in touch with market trends in terms of healthy eating. Location of the restaurant also has an effect on the outcome of potential of restaurants to offer healthy eating 
products. Restaurants located in areas whose population has characteristics that direct their food choices to healthy eating are bound to exhibit improved customer outcomes as opposed to areas with most of the population lacking these attributes. In addition to restaurant type and location, ownership is a key factor in predicting the healthy eating products on offer and its influence on customer outcomes. Owners who have a conviction of investing in healthy eating products are more likely to offer products that meet customer needs hence influence customer outcomes.

\section{Research Methodology \\ 3.1 Data Collection and Sampling}

A list of restaurants operating in Nairobi was traced through trip advisor and hello.com. Nairobi has 317 restaurants, including 147 with healthy food labels (Kenya Association of Hotels and Caterers, 2014). All the 147 restaurants with healthy food labels were purposively selected and included in the sampling frame as the results and information from the current study would be more generalizable. Because of the time and financial constraints of the research, not all restaurants with healthy food labels could be approached. A sample of 74 restaurants was drawn from the population via simple random sampling technique. Structured questionnaires were sent out to 296 heads of departments. In total, completed questions were received from 287 respondents. This represents a response rate of $97 \%$.

\subsection{Measures}

All measures in the current study were drawn from previous research and aligned with the conceptual aspects of each construct (Jun et al., 2014; Krystallis et al., 2003; Roininen et al., 1999; Tudoran et al., 2009; Zeithaml et al., 1996). The questionnaire sought information concerning the following issues: (a) the healthy eating products on offer (Jun et al., 2014; Tudoran et al., 2009); (b) customer outcomes measured by healthy eating product categories on offer, customer awareness, number of customers sampling healthy eating products and customer satisfaction, and number of healthy eating product customer consume on repeat patronage (Jun et al., 2014; Krystallis et al., 2003); and (c) influence of age, location and restaurant location on the relationship between healthy eating products and customer outcomes (Jun et al., 2014; Roininen et al., 1999; Zeithaml et al., 1996). Numeric 5-point Likert scales were used with descriptive anchors to measure the variables in the current study. The anchors were utilized to force respondents to focus on the factor in healthy eating products and customer outcome.

\subsection{Data Analysis}

The Statistical Package for Social Sciences (SPSS) was used to explore the data. The researchers used descriptive statistics to analyze the demographic characteristics of the respondents and to identify healthy eating products on offer in restaurants in Nairobi, Kenya. Principal factor analysis was used to assess the dimensionality, reliability, and validity of the scales. Finally, multiple logistical regression was used to investigate the relationship between healthy eating and customer outcomes as well as the effect of control variables.

\section{Results}

\subsection{Descriptive Statistics}

Table 1 provides some information about the respondents' demographic characteristics. Majority of the study participants were males $(178,62.02 \%)$ aged $26-35$ years $(146,50.87 \%)$ and holders of Certificate/Diploma level of education $(132,45.99 \%)$. These results provide evidence that the restaurant sector in Kenya constitutes masculine environment. The implication is a strong gender differentiation in which the male population is competitive and assertive relative to the female population. 
Table 1: Demographic characteristics of the respondents.

\begin{tabular}{lrr}
\hline Characteristic & Frequency & Valid Percent (\%) \\
\hline Gender & 178 & 62.02 \\
Male & 109 & 37.98 \\
Female & $\mathbf{2 8 7}$ & $\mathbf{1 0 0 . 0 0}$ \\
Total & & \\
& & \\
Age (in years) & 58 & 20.21 \\
25 and below & 146 & 50.87 \\
$26-35$ & 20 & 6.97 \\
$36-45$ & 63 & 21.95 \\
46 and above & $\mathbf{2 8 7}$ & $\mathbf{1 0 0 . 0 0}$ \\
Total & & \\
& & 37.98 \\
Level of Education & 109 & 45.99 \\
Secondary and below & 132 & 16.03 \\
Certificate/Diploma & 46 & $\mathbf{1 0 0 . 0 0}$ \\
Bachelor's degree and & & \\
above & $\mathbf{2 8 7}$ & \\
Total & & \\
\hline
\end{tabular}

\subsection{Psychometric Properties}

Principal factor analysis (PCA) with Varimax was used to assess the dimensionality, reliability, and validity of the scales, consisting of 10 factors. Table 2 shows the measurement analysis results, including loadings, composite reliabilities (CR), average variances extracted (AVE), and fit indices. Composite reliabilities (CR) were calculated and as Table 2 shows the values range from .74 to .87 , all exceeding .70, which is the acceptable CR level according to several authors (e.g. Bagozzi and Yi, 1988). The values for AVE from each construct (ranging from .68 to .90) also exceeded the threshold level (.5). All item loadings ranging from .68 to .78 are significant at the $1 \%$ significance level, indicating convergent validity (Barclay et al., 1995).

Table 2: Reliabilities, factor loads and AVE scores.

\begin{tabular}{lccc}
\hline Variable & Item Loading & CR & AVE \\
\hline Healthy Eating Products & .73 & .74 & .83 \\
Increase in customer numbers & .75 & .75 & .78 \\
Increase in product request & .72 & .87 & .88 \\
Customer satisfaction & .74 & .78 & .78 \\
Customer loyalty & .74 & .87 & .90 \\
Meeting friends & .72 & .76 & .76 \\
Convenience of restaurant location & .78 & .80 & .68 \\
Ease of access & .68 & .87 & .75 \\
Well known owner & .71 & .75 & .81 \\
Age of restaurant & .73 & .86 & .69 \\
\hline
\end{tabular}

Note. $\mathrm{CR}=$ composite reliabilities; $\mathrm{AVE}=$ average variances extracted.

\subsection{Mean Scores}

Table 3 shows means and standard deviations of the study variables. Most of the variables had very high means suggesting that they were highly rated by the respondents. All variables had 
standard deviations less than 1.00 indicating that the perceptions of the respondents concerning healthy eating, customer outcomes and control variables were generally similar across the restaurants studied.

Table 3: Mean scores of study variables.

\begin{tabular}{lcccc}
\hline \multicolumn{1}{c}{ Factor } & $\begin{array}{c}\text { Minimum } \\
\text { Statistic }\end{array}$ & $\begin{array}{c}\text { Maximum } \\
\text { Statistic }\end{array}$ & Mean & $\begin{array}{c}\text { Std. } \\
\text { Deviation }\end{array}$ \\
\hline Healthy Eating Products & 1.00 & 5.00 & 4.66 & 0.74 \\
Increase in customer numbers & 1.00 & 5.00 & 4.65 & 0.73 \\
Increase in product request & 1.00 & 5.00 & 3.76 & 0.67 \\
Customer satisfaction & 1.00 & 5.00 & 3.37 & 0.59 \\
Customer loyalty & 1.00 & 5.00 & 4.50 & 0.64 \\
Meeting friends & 1.00 & 5.00 & 4.50 & 0.76 \\
Convenience of restaurant location & 1.00 & 5.00 & 4.78 & 0.98 \\
Ease of access & 1.00 & 5.00 & 4.59 & 0.93 \\
Well known owner & 1.00 & 5.00 & 4.66 & 0.60 \\
Age of restaurant & 1.00 & 5.00 & 4.52 & 0.73 \\
\hline
\end{tabular}

The first objective of the current research was meant to identify healthy eating products on offer in restaurants in Nairobi City County. Results show that traditional foods (food product domesticated to a certain community), medicinal foods (a food product believed to prevent or cure an illness), and products cooked using healthy cooking methods were the most popular healthy eating products followed, vegetarian products, gluten free and sea food products in that order.

The second objective of the study was to examine the relationship between healthy eating products and customer outcomes. Therefore, multiple logistical regression analysis was conducted with the healthy eating products as the independent variables and customer outcomes as dependent variables. This research used the criteria of the probability of $\mathrm{F}$ at the 5\% level (.05 significance). Furthermore, the authors checked for multicollinearity and variance inflation factor (VIF) values, which indicated no problems because all VIF values were less than 1.04 (in all four regression analyses). These VIF values are well under the critical level of 10, as suggested by Hair et al. (1998). The adjusted $\mathrm{R}^{2}$ was .28 for increase in customer numbers, .34 for increase in product request, .29 for customer satisfaction and .45 for customer loyalty. All the adjusted $\mathrm{R}^{2}$ of the current study appear satisfactory in comparison to other similar studies levels. The residual plots were also examined and no problems were accounted. The four different dimensions of customer outcomes were strongly linked to a number of consumption of healthy eating products. Table 4 reports the results of the regression analyses, which indicate that all equations are highly significant. These results are discussed below.

Table 4: Results of regression analyses (Standardized Regression Coefficients).

\begin{tabular}{lcccccccc}
\hline \multicolumn{1}{c}{$\begin{array}{c}\text { Healthy Eating } \\
\text { Products }\end{array}$} & $\begin{array}{c}\text { Increase in } \\
\text { customer } \\
\text { numbers }\end{array}$ & $\begin{array}{c}\text { Increase in } \\
\text { product } \\
\text { request }\end{array}$ & $\begin{array}{c}\text { Customer } \\
\text { satisfaction }\end{array}$ & $\begin{array}{c}\text { Customer } \\
\text { loyalty }\end{array}$ \\
\cline { 2 - 9 } & $\beta$ & $p$ value & $\beta$ & $p$ value & $\beta$ & $p$ value & $\beta$ & $p$ value \\
Traditional & .16 & .00 & .30 & .00 & .21 & .01 & .13 & .03 \\
Medicinal & .32 & .00 & .22 & .00 & .30 & .00 & .40 & .00 \\
Foods prepared using & .25 & .04 & .25 & .02 & .21 & .01 & .35 & .00 \\
healthy cooking methods & & & & & & & &
\end{tabular}




\begin{tabular}{lcccccccc}
\hline Vegetarian products & .22 & .00 & .32 & .00 & .17 & .03 & .29 & .00 \\
Gluten free products & .11 & .00 & .12 & .03 & .30 & .00 & .15 & .02 \\
Seafood & .10 & .00 & .09 & .00 & .17 & .00 & .29 & .00 \\
Low fat Foods & .24 & .02 & .42 & .00 & .14 & .02 & .22 & .00 \\
Organic Foods & .22 & .00 & .34 & .02 & .22 & .00 & .15 & .00 \\
Adjusted R & & .28 & & .34 & & .29 & & .45 \\
\hline
\end{tabular}

Note: Checks for multicollinearity and variance inflation factor (VIF) values indicate no problems (all VIF values less than 1.03).

The third objective of this study was to establish the influence of control variables on customer outcomes. Table 5 reports these relationships. Only two variables such as meeting friends and convenience of restaurant location had a significant influence on customer outcomes. The adjusted $\mathrm{R}^{2}$ for the significant relationships were .21 and .18 .

Table 5: Influence of control variables test.

\begin{tabular}{llcc}
\hline Variables & \multicolumn{2}{c}{ Customer outcomes } & ${\text { Adjusted } \mathbf{R}^{\mathbf{2}}}$ \\
\cline { 2 - 4 } Meeting friends & $\beta$ & $p$ value & .21 \\
Convenience of restaurant & .39 & 0.00 & .18 \\
location & .27 & 0.00 & \\
Ease of access & & & \\
Well known owner & .42 & 0.07 & \\
Age of restaurant & .44 & 0.10 & \\
\hline
\end{tabular}

Note: $\mathrm{p}<.05$

\section{Conclusion, Implications and Limitations}

Findings of this study show that healthy eating products offered by the sampled restaurants were: traditional food products, medicinal and healthy cooked products; vegetarian food products; gluten free foods products; and sea food products. The results are consistent with the suggestion by Zick et al., (2010) that restaurants should consider traditional cooking styles and recipes as major components of healthy eating products. The current research confirms that the main concern for customers when selecting a healthy meal when they dine out is lowfat and non-genetically modified ingredients (Legrand and Sloan, 2006). These findings are in tandem with earlier studies that found traditional and low fat/healthy cooked products as key elements of healthy eating (Legrand and Sloan, 2006; Zick et al., 2010). According to Angelfire (2013), customers are increasingly adopting vegetarian diets which they refer to as the 'in thing'. Carla and Wartson (2003) agrees with the study findings that view the vegetarian food concept as a mentalist rather than a materialistic food consumption approach. The need to lead a healthy lifestyle is the reason for the increase in the number of people who adopted the vegetarian diet. As Winston (2009) avers, the benefits of vegetarianism include lower risk of cardiovascular disease; an improved glycemic control for individuals with type 2 diabetes; thinner or lean bodies with lower serum cholesterol; and lower blood pressure. The Harvard Medical School (2013) has also found that more people have adopted gluten free diets to lead a healthy lifestyle. Gluten free diets control obesity, prevent diabetes, cardiovascular diseases and other lifestyle illnesses. Kearny (2010) has also revealed a tremendous rise in the consumption of sea food and further predicts the rise in the consumption of sea food towards 2050s compared to any other protein sources. This rise is associated to the fact that most people considered sea food as a healthy protein because fish, especially the pelagic type, was described as rich in long chain omega -3 fatty acids essential for cardiovascular health. 
The four different dimensions of customer outcomes were strongly linked to a number of consumption of healthy eating products. Customer satisfaction is attributed to either variety or quality of healthy eating products on offer in restaurants. Although Stubenitsky et al., (1999) reported that the market segment of customers who desired and used nutritional information on menus dined out frequently, the researchers did not clarify on the extent of dining out frequency. They also did not clarify whether these customers sampled healthy eating products on every occasion that they ate out. Acording to the findings of this study, market response, frequency of purchase, and market size per day are characteristics of the market which contributed to healthy eating products. Mills and Thomas (2008) argue that products on offer in eating outlets reflect in customer response. Customer outcomes for healthy eating products can be increased if eating outlets assisted customers to select healthy meal choices (Galliciano, et al., 2012). Customer satisfaction towards a brand is attained through attribute evaluation (Kotler \& Keller, 2011). Customer loyalty is an outcome of customer satisfaction (Khan, 2013; Kotler and Keller, 2011). Since the relationship between healthy eating product consumption and customer satisfaction was significant it is equally expected that satisfaction would be replicated in customer loyalty.

The results show that only two control variables meeting friends and convenience of restaurant location had a significant influence on customer outcomes. The highest proportion of healthy eating product customers went to the sampled restaurants to meet friends. Increase in information sharing made possible by technological advancement such as the internet as well as the media make it easier for friends to keep in touch. The advent of internet and affordable smart phones enable people to form social groups and share ideas on social networks in terms eating out options. The second most important factor was convenience of location. This was attributed to the fact that Nairobi city is the centre of business for the entire country and region. It is also the location where most activities in the country take place. Restaurants located close to the places of work of healthy eating product customers were considered easy to access. Customers could therefore easily access such facilities and order office or house deliveries. Other control factors including age and restaurant owner's familiarity were insignificant as moderators of healthy eating relationship - customer outcomes. Age of a restaurant can't expressly influence products and the market unless other elements such as capacity and restaurant objectives are considered. A well known owner may not directly influence products and the market without other factors such as conviction of the owner based on their history and reputation.

This study made major contributions to the body of knowledge, theory and practice in the area of healthy eating and customer outcomes by clearly identifying products that customers consider as healthy food products. The study further reveals factors that attract customers to restaurants offering healthy eating products including meeting friends and convenience of restaurant location. The study further contributes to the theory of consumer behavior by stating that customer's personal characteristics influence their food selection habits and customer outcomes. Although our findings expand the extant knowledge on the impact of healthy eating on customer outcomes in the restaurant sector, we recognize several limitations that must be taken into account when generalizing our results. The design of our experiment provides insight into the Nairobi City healty eating restaurants - one specific segment with customers culture and experience-but it remains unclear whether findings would be similar for other restaurant categories and hospitality industry in general. Another avenue for further research would be to test the applicability of our findings across other urban location such as Mombasa, Kisumu, and Eldoret. 


\section{References}

Angelfire (2013). Beef... and why it shouldn't be what's for dinner. America: American Diabetic Association.http://www.angelfire.com/pe2/johnandbecca/vegpaper.htm. Accessed on 11 April 2017.

Angell, S.Y., \& Silver, G.P. (2008). Calorie labeling in New York City restaurants: An approach to inform consumers, available at: www.cspinet.org/reports/. Accessed on 3 August 2016.

Bagozzi, R. P., \& Yi, Y. (1988). On the evaluation of structural equation models. Journal of the Academy of Marketing Science, 16(1), 74-94.

Bakker, M.A. (2006). Hotel restaurant concept selection considerations: Which factors to take into account?. UNLV Theses, Dissertations, Professional Papers, and Capstones. http://digitalscholarship.unlv.edu/thesesdissertations/596.

Barclay, D.W., Thompson, R., \& Higgins, C. (1995). The partial least squares (PLS) approach to causal modeling: Personal computer adoption and use an illustration. Technology Studies, 2(2), 285-309.

Benelam, B. (2009). Calories on the menu. Nutrition Bulletin, 34(3), 289-90.

Cahill, D. J. (2006). Lifestyle Market Segmentation. NY: The Haworth Press.

Carla, S., \& Wartson, J. (2003). Privilege, protest, and changing worldview: A look at veganism through the Dudley Co-op. Havard, USA.

Davies, G.J., \& Smith, J.L. (2004). Nutrition and food science. Bradford, 34(2), 80-82.

Fishbein, M., \& Ajzen, I. (2010). Predicting and changing behavior: The reasoned action approach. New York: Taylor \& Francis.

Galliciano, R., Blomme, J. R., \& Rheede, V. A. (2012). Consumer response to nutrition information menu labeling in full-service restaurants: Making the healthy choice. In Joseph S. C. (ed.), Advances in Hospitality and Leisure (Volume 8). Emerald Group Publishing Limited, pp.109-125, DOI: 10.1108/S1745-3542(2012) 0000008010.

Hair, J., Anderson, R., Tatham, R., \& Black, W. (1998). Multivariate data analysis ( ${ }^{\text {th }}$ Ed.). Upper Saddle River, NJ: Prentice Hall.

Harvard Medical School (2013). Going gluten just because. Harvard Health Publications Healthwise (2017). Healthy eating: Influences on eating behavior: http://www.webmd.com/parenting/tc/healthy-eating-influences-on-eating-behaviortopic. Accessed on 24 June 2016.

Hwang, J., \& Lorenzen, C.L. (2008). Effective nutrition labeling of restaurant menu and pricing of health menu. Journal of Food Service, 19 (5), 270-276.

Josiam, B.M., \& Foster, C.R. (2009). Nutritional information on restaurant menus: Who cares and why restaurants should bother. International Journal of Contemporary Hospitality Management, 21 (7), 876-981.

Jun, J., Kang, J., \& Arendt, S.W., (2014). The effects of health value on healthful food selection intention at restaurants: Considering the role of attitudes toward taste and healthfulness of healthful foods. Apparel, Events and Hospitality Management Publications. 42. https://lib.dr.iastate.edu/aeshm_pubs/42.

Kearney, J. (2010). Food consumption trends and drivers. The Royal Society, Philosophical Transactions B. DOI: 10.1098/rstb.2010.0149.

Kenya Association of Hotels and Caterers (2014). Hotels in Nairobi. Kenya: Ministry of Tourism.

Khan, S. (2013). Determinants of customer retention in hotel industry. Journal of Applied Economics and Business, 1(3), 42-64. 
Kim, W. G., Lee, Y. K., \& Yoo, Y. J. (2006). Predictors of relationship quality and relationship outcomes in luxury restaurants. Journal of Hospitality \& Tourism Research, 30(2): 143169.

Kotler, K. P., \& Keller, L. (2011). Marketing management. New York: Pearson Prentice Hall.

Kotler, P. (2011). Reinventing marketing to manage the environment imperative. Journal of Marketing, 75 (4), $132-135$.

Krystallis, A., Aranitoyannis, I. S., \& Kapirti, A. (2003). Investigating Greek consumers'attitudes toward low-fat products: A segmentation study. International Journal of Food Sciences and Nutrition, 54 (3), 219-233.

Legrand, W., \& Sloam, P. (2006). Customers' preferences to healthy meals. In Joseph S.Chen(ed.), Advances in Hospitality and Leisure (Volume 2). Emerald Group Publishing Limited, pp.265-273. DOI: 10.1016/S1745-3542(05)02014-X.

Lone, T. A., Pence, D., Levi, A. E., Chan, K. K., \& Bianco-Simeral, S. (2009). Marketing healthyfood to the least interested consumers. Journal of Foodservice, 20, 90-99.

Mackison, D., Wrieden, W.L., \& Anderson, A.S. (2009). Making an informed choice in the catering environment: What do consumers want to know? Journal of Human Nutrition and Dietetics, 22 (5), 567-573.

Mamalis, S. (2009). Critical success factors of the foodservice industry. Journal of International Food \& Agribusiness Marketing, 21(2-3)191-206.

Michaelidou, N., \& Hanssan, L. M., (2008). The role of health consciousness, food safety concern and ethical identity on attitudes and intentions towards organic food. International Journal of Consumer Studies 32 (2), 163-170.

Mills, J.E., \& Thomas, L. (2008). Assessing customer expectations of information provided on restaurant menus: A confirmatory factor analysis approach. Journal of Hospitality \&Tourism Research, 32 (1), 62-88.

Pantelidis, I. S. (2010). Electronic meal experience: A content analysis of online restaurant comments. Cornell Hospitality Quarterly, 51(4), 483-491.

Roininen, K., Lähteenmäki, L., \& Tuorila, H., (1999). Quantification of consumer attitudes to health and hedonic characteristics. Appetite, 33 (1), 71-88.

Scarpa, J., (2010). Uno Chicago Grill's healthy menu makeover. Nation's Restaurant News. Available online at http://www.nrn.com/article/uno-chicago-grills-healthy menumakeover. Accessed on 10 August 2017.

Shaw, M. (2002). Location, location, location. Spa Marketing Systems, Ltd. Retrieved March 12, 2016) from http://www.spamarketing.co.uk/pdf/RestSeg.pdf.

Stubenitsky, K., Aron, J.I., \& Catt, S.L. (1999). The influence of recipe modification andnutritional information on restaurant food acceptance and macronutrient intakes. PublicHealth Nutrition, 3 (2), 201-209.

Tromp, D. M., Brouha, X. D. R., Hordijk, G. J., Winnubst, J. A. M., Gebhardt, W. A., van der Doef, M. P., \& Leeuw, J. R. J. (2007). Medical care-seeking and health-risk behavior in patients with head and neck cancer: The role of health value, control beliefs, and psychological distress. Health Education Research, 20 (6), 665-675.

Tudoran, A., Olsen, S. O., \& Dopico, D. C. (2009). The effects of health benefit information on consumer health value, attitudes, and intentions. Appetite, 52 (3), 568-579.

Winston, J. (2009). Health effects of vegan diets. American Nutrition Society. America: ADA.

World Health Organisation (2009). Obesity. Available at www.who.int/topics/obesity/en/. Accessed on 10 August 2017.

World Health Organization (2012). New data highlight increases in hypertension, diabetes incidence. International Journal of Health Care Quality Assurance, 25 (7), 625-644.

Wu, H. W., \& Sturm, R. (2014). Changes in the energy and sodium content of main entrées in US chain restaurants from 2010 to 2011. Journal of the Academy of Nutrition and Dietetics, 114 (2), 209-219. 
Zeithaml, V., Berry, L., \& Parasuraman, A. (1996). The behavioral consequences of service quality. Journal of Marketing, 60, 31-46.

Zick, A., Wake, Y., \& Reeves, S. (2010). Nutrition labeling in restaurants: A UK-based case study. Nutrition \& Food Science, 40 (6), 557-565. DOI: 10.1108/eb058808. 